\title{
Improving patient safety in transfusion medicine: contemporary challenges and the roles for bedside and laboratory biovigilance in addressing them
}

\author{
This article was published in the following Dove Press journal: \\ International Journal of Clinical Transfusion Medicine \\ 10 July 2014 \\ Number of times this article has been viewed
}

\author{
Chester Andrzejewski Jr' \\ Darlene Cloutier' \\ David Unold ${ }^{2}$ \\ Richard C Friedberg' \\ 'Transfusion Medicine Services, \\ Department of Pathology, Baystate \\ Medical Center, Baystate Health, \\ Springfield, MA, ${ }^{2}$ Department of \\ Laboratory Medicine, Yale University \\ School of Medicine, New Haven, \\ CT, USA
}

\begin{abstract}
Throughout the history of hemotherapy (HT), various challenges and concerns have been encountered in its practical application. When viewed using a prismatic lens of history, recurrent themes regarding adverse HT sequelae separate and become apparent. These can be broadly classified into three categories: infectious, noninfectious, and administrative/logistical. Using the HT care map as a frame of reference along with its associated rites, we examine the contemporary spectrum of HT adverse events and concerns, and some approaches as to how these may be addressed from bedside and laboratory medicine biovigilance perspectives enhancing patient care and blood transfusion safety. Although our vantage point is from an academic community hospital venue, the issues and concerns identified are germane to many if not all transfusion-medicine practice environments. Included among the subjects we explore are patient/ specimen identification issues, blood-management initiatives, unrecognized and/or unreported suspected transfusion reactions, transfusion-associated adverse pulmonary sequelae (including transfusion-related acute lung injury and transfusion-associated circulatory overload), expanded applications of electronic health records and issues regarding their "meaningful use" and interinstitutional "digital compatibilities", biovigilance integration of electronic data networks within and between health care entities, and anticipated workforce contractions secondary to projected declines in the availability of qualified laboratory professionals. Cooperative initiatives between accreditation and regulatory entities, blood collectors and suppliers, hospital laboratory transfusion services and health care providers involved in the bedside care of the patient offer the best means in further mitigating adverse HT sequelae and potential nonconformities that may arise in the daily operations of contemporary hospital blood banks and transfusionmedicine services.
\end{abstract}

Keywords: hemotherapy, transfusion history, reactions, risk mitigation

\section{Introduction}

Since its earliest introduction into routine clinical practice, blood transfusion has both comforted and confounded physicians in their attempts to improve the health and well-being of their patients. From that early foundational period, although blood's lifesaving attributes could clearly be demonstrated in remarkable ways, its related adverse effects severely compromising patients were also observed, negatively impacting patient outcomes and giving clinical pause to stalwart advocates of the nascent and evolving technologies associated with hemotherapy (HT). Compared to the challenges confronting transfusionists in those earlier days, the challenges confronting
Correspondence: Chester Andrzejewski Jr Transfusion Medicine Services, Department of Pathology, Baystate Medical Center, Baystate Health, 759 Chestnut Street, Springfield, MA OI 199, USA

Tel +I 4137944602

Fax + I 4137942721

Email chester.andrzejewski@bhs.org
International Journal of Clinical Transfusion Medicine 20।4:2 45-57 
transfusion medicine (TM) specialists today are in some ways remarkably similar yet distinctly different, requiring approaches never imagined by the early transfusionists. In this paper, we examine some of these challenges and potential strategies to address them successfully.

We begin our journey by examining the historical roots of TM, followed by a more detailed examination of the literature related to the hazards of HT, comparing practitioners' concerns promulgated in the past 100 years to ones currently espoused. From there, we review various facets of the HT care map and the " 12 rites" of HT, and how these may relate to targets for improving the safety of transfusions. Finally, we explore possible approaches that might be considered in meeting some of the challenges to enhanced HT safety. Throughout the discourse, where appropriate, we also offer insight from lessons learned from our own clinical experiences, highlighting select aspects within the identified themes. Although physicians and researchers from all backgrounds and cultures have contributed to our knowledge base regarding adverse transfusion hazards, the focus of our narrative will be predominantly on those publications obtained from the English-language literature.

\section{Historical overview of HT}

The history of HT can be arbitrarily and broadly subdivided into four temporally unequal periods (ie, the foundational years, the ascent of components, the era of infections, and the age of biovigilance).$^{1-8}$ Key events associated with each of these temporal demarcations are highlighted in Table 1. The acquisition of fundamental knowledge regarding the nature of blood, its life-sustaining role in living beings, its circulation throughout the body, and the recognition of its potentially lifesaving therapeutic infusion characterize these critical early foundational years. The journey to such knowledge itself was predicated on even earlier understandings obtained via practical in situ experiences by countless medical practitioners over several millennia, but it was only through the deliberate investigational application of the "scientific method" that this "artful" foundation was reinforced and fortified empirically. ${ }^{2,3,5}$ In the latter part of the foundational years, the discovery of the nature of blood-group antigenicity along with fundamental immunologic advances in our knowledge of antibodies and complement proteins further strengthened the serologic foundational underpinnings of HT. ${ }^{1-6}$ As HT became more common, the recognition of both its benefits and risks led to increased appreciation of associated medicolegal liability aspects, and the introduction of governmental regulatory oversight (at first local but

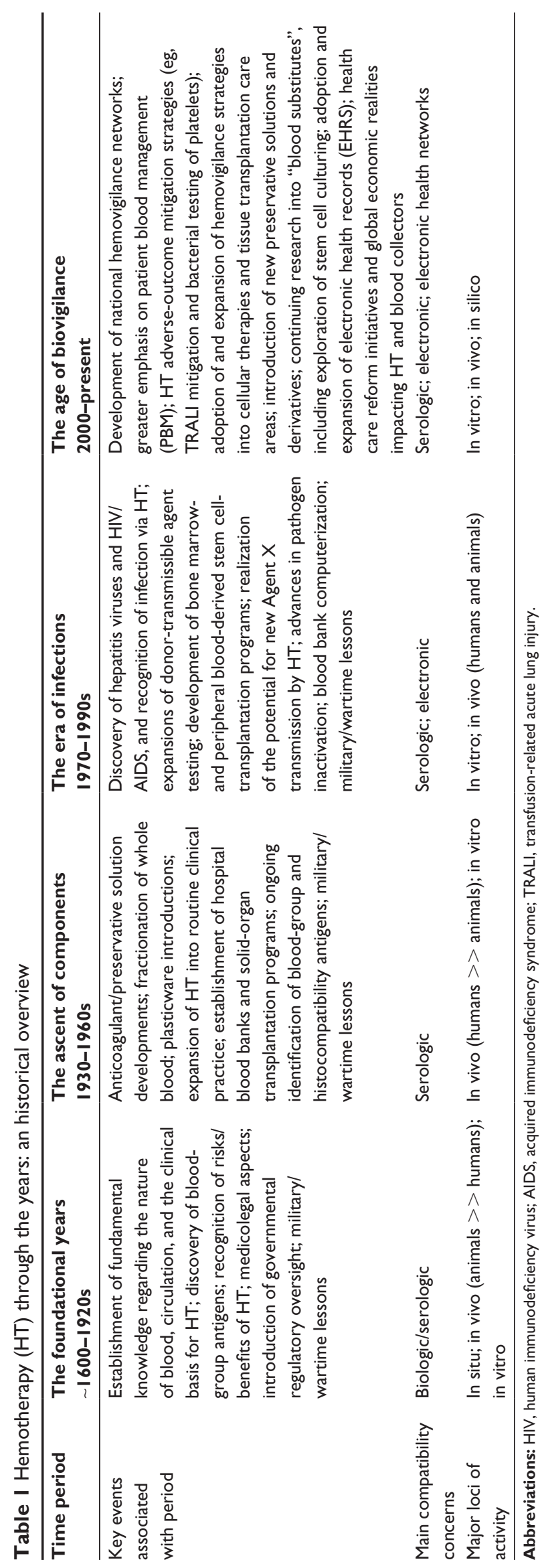


then national) occurred. ${ }^{5,7}$ Unfortunately, as with other areas of human endeavor, lessons learned through military conflicts and wartime also advanced the discipline. ${ }^{6,8-10}$

Building on these earlier advances, in the time period characterized as the ascent of components, continuing research into anticoagulant and preservative solutions along with the development of whole-blood fractionation strategies augmented the expansion of HT into routine clinical practice. ${ }^{3,6}$ The advent of hospital blood banks (BBs) resulted from a recognition of the need to have a reliable inventory of blood quickly available near critical care settings for patients that might require acute transfusions, eg, obstetrical and surgical cases. With an increasing understanding of immunology, ongoing identification of non-ABO blood-group and histocompatibility antigens proceeded at a quick pace. Again, lessons learned from human conflicts contributed to our knowledge base.

Although the transmission of various infections was well appreciated since transfusion's earliest days, it was during the years characterized as the era of infections that the sobering reality of this darker side of blood transfusion captured not only the medical establishment's renewed attention but the general public's focus as well. ${ }^{8,11}$ The discovery of the various hepatitis viruses and the human immunodeficiency virus (HIV) were tours de force of the application of the scientific method and emerging biotechnologies in the examination of a heretofore-routine lifesaving therapeutic intervention that now appeared to be a double-edged sword. Lessons learned from those trying times continue to reverberate throughout the TM community to this day, and the knowledge gained and approaches taken to dealing with these issues catalyzed the development of hemovigilance networks worldwide, the continuing quest for pathogen-inactivated blood components, and the disconcerting realization of the possibility of new pathogens being found as potential agents of blood-associated disease transmissions not detectable by the expanded donorscreening strategies currently in place. ${ }^{11-13}$ During this time, advances in hematopoietic stem cell harvesting and transplantation also occurred, setting the stage for the later development of the promising area of regenerative medicine. Paralleling advances outside the medical establishment, the incorporation of computerization into BBs was a significant milestone, and its introduction heralded a new type of potential compatibility concern (ie, electronic) for TM services (TMSs). ${ }^{14,15}$

By the dawn of the third millennium, HT had entered the age of biovigilance. As with predecessor time frames, in addition to some previously identified key events that continued to be of importance to practitioners, new issues and challenges presented themselves. The multiplication and evolution of national hemovigilance networks, greater emphasis on patient blood-management programs, adoption of various HT adverse-outcome mitigation strategies, and health carereform initiatives, along with global economic constraints affecting both hospitals and blood suppliers, characterized the early part of the period. ${ }^{8,16}$ The application and expanded use of electronic health records (EHRs) and the huge influx of "big data" in HT were also signature events. ${ }^{17}$ Unlike prior periods, major compatibility issues now also included intercommunicability concerns between institutional electronic health networks, governmental regulatory oversight, and third-party payer systems that continue to evolve.

\section{HT hazards and concerns through the years}

Using a similar approach as the one just applied in describing the key events in the history of HT, an outline of the major concerns regarding the chief hazards of blood transfusion on a temporal basis can be constructed (Table 2). Although the order of concern of some of the hazards may vary over the HT timeline, remarkably when viewed in such a manner, certain recurrent themes appear that are relevant to this day., ${ }^{411,16,18-24}$ Three major divisions of hazards and/or concerns can be identified: infectious, noninfectious, and logistical/administrative. These contemporary HT challenges signify core issues confronting TM specialists and their bedside colleagues in their daily operations as they attempt to enhance HT safety. Although the frequencies of many have been appreciably reduced, it is a discomforting reality that these challenges have not been fully eliminated, and indeed can still be encountered with HT in various health care settings in both well-established nations and countries still early in their national development. We examine a number of these challenges in further detail, but before doing so we need to explore the HT care map, the "rites" associated with transfusions, and a general classification system of adverse transfusion events.

\section{The hemotherapy care map}

A clinical care map is a description of a strategy or approach used to guide health care professionals in the delivery of multidisciplinary care or therapeutics, and is well known and used throughout the nursing profession. Although the pictorial format of the care map for uncomplicated HT (UHT) may vary depending on such factors as the locus of care, eg, outpatient transfusion clinics versus perioperative 


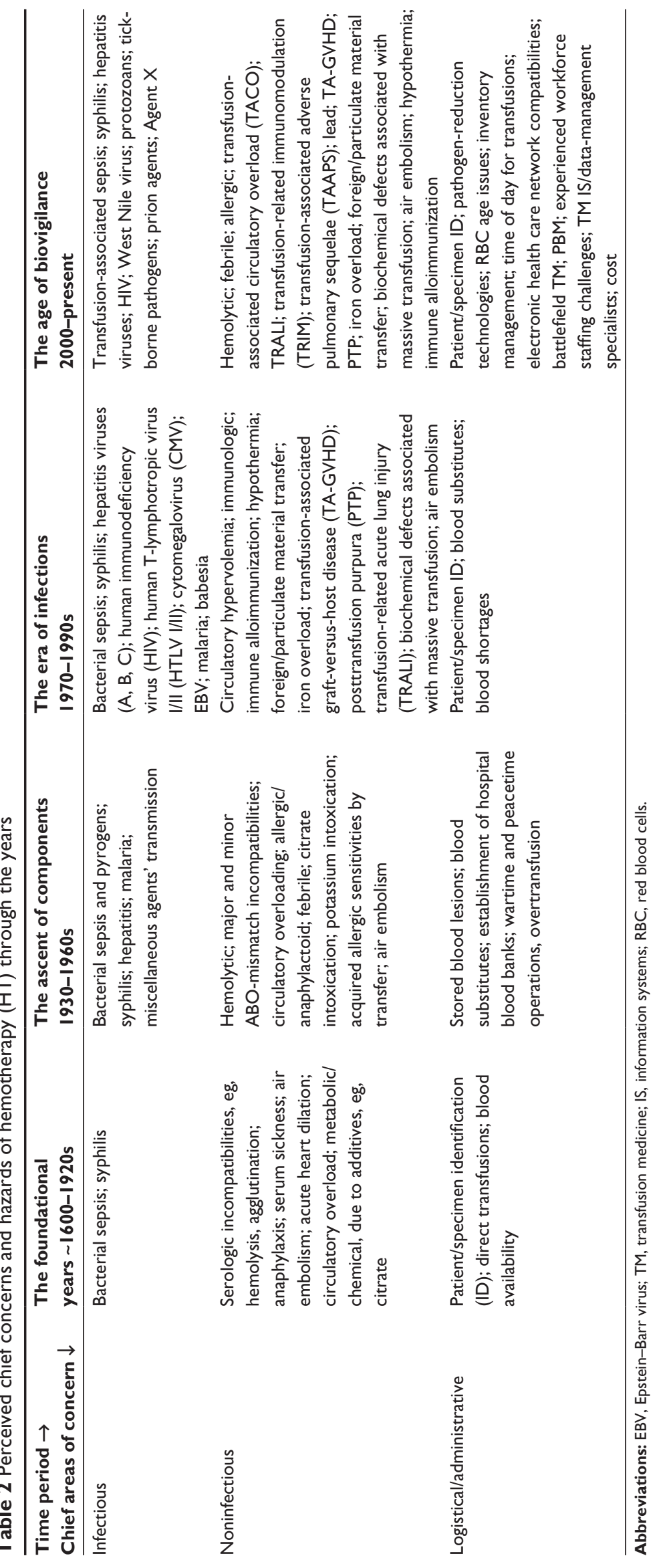


settings, it typically would include information regarding the various personnel involved in the activity, the tasks needed to be performed, and key decision-point junctures for the successful delivery of that care. ${ }^{25}$ Conceptually, the UHT care map is very much related to flow diagrams depicting the transfusion chain of events or the stages of the clinical transfusion process. ${ }^{25-27}$ A section of a care map for UHT detailing the major diagnostic, therapeutic, and biovigilance activities needing to be performed during the various phases of the transfusion event is shown in Figure 1. Depending on the phase of transfusion activity, key assessments and patient monitoring need to be accomplished. The majority of such activities are directly focused on patient safety and the prevention of adverse transfusion sequelae.

\section{The "rites" of HT}

Embodied in the design of the care map are the key "rites" of HT (Table 3), or the critical parameters that need to be accounted for to ensure the delivery of safe and efficacious transfusions. Aspects of some of these "rites" are related in part to previously described patient-focused "rights" of transfusion. ${ }^{28,29}$ The 12 "rites" identified here, however, pertain not only to patients but to providers (both individuals and institutions), and encompass the major process-related and procedural aspects of HT. For example, it is assumed that the provider has the proper knowledge of the patient and the HT appropriate for that interval of care, including the optimal types, amounts, and rates of administration of the pertinent blood products to be transfused. It is also assumed that the intended HT is being delivered to the right patient in the right care setting at the most appropriate time, with the proper clinical monitoring, follow-up, and documentation. Unfortunately this is not always the case, and the spectrum of potential problems resulting from deviations or nonconformities in the various HT "rites" constitutes a large part of historical and contemporary concerns regarding HT.

\section{Classification of adverse transfusion events}

The occurrence of HT adverse events can be categorized in a variety of ways. ${ }^{23-25}$ One such format is shown in Table 4. Depending on the approaches used by BBs in their evaluation

\begin{tabular}{|c|c|c|c|c|}
\hline \multicolumn{2}{|c|}{ Pre-HT Phase } & \multirow{2}{*}{$\begin{array}{c}\text { Intra-HT Phase } \\
\text { II }\end{array}$} & \multicolumn{2}{|c|}{ Post-HT Phase } \\
\hline IA & IB & & IIIA & IIIB \\
\hline $\begin{array}{l}\text { - Assess hemotherapy } \\
\text { need. } \\
\text { - Select appropriate } \\
\text { component. } \\
\text { - Review hemotherapy } \\
\text { and adverse sequelae } \\
\text { history. } \\
\text { - Perform accurate/ } \\
\text { correct patient-and } \\
\text { specimen- } \\
\text { identification checks. } \\
\text { - Obtain transfusion } \\
\text { consent. } \\
\text { - Submit appropriate } \\
\text { orders for component } \\
\text { preparation and } \\
\text { transfusion. } \\
\text { - Perform appropriate } \\
\text { serologic and } \\
\text { compatibility studies } \\
\text { in the blood bank. } \\
\text { Biovigilance activities: } \\
\text { prospective/concurrent } \\
\text { reviews, computerized } \\
\text { alerts regarding HT } \\
\text { orders and laboratory } \\
\text { values' threshold } \\
\text { triggers and risk alerts } \\
\text { for select patient } \\
\text { populations. }\end{array}$ & $\begin{array}{l}\text { - Assess intravenous site } \\
\text { access. } \\
\text { - Procure necessary } \\
\text { equipment. } \\
\text { - Ensure consent was } \\
\text { obtained. } \\
\text { - Obtain blood from blood } \\
\text { bank. } \\
\text { - Identify recipient. } \\
\text { - Educate patient. } \\
\text { - Perform required patient } \\
\text { and blood unit- } \\
\text { identification checks. } \\
\text { - Measure and record } \\
\text { initial vital-sign values } \\
\text { (VSVs). } \\
\text { - Begin transfusion. }\end{array}$ & $\begin{array}{l}\text { - Record and review (at selected } \\
\text { intervals) fluid status, clinical } \\
\text { assessments, and VSVs, with } \\
\text { appropriate action as needed. } \\
\text { - Monitor for acute suspected } \\
\text { transfusion reactions (STRs), } \\
\text { and report to responsible } \\
\text { medical staff and blood bank. } \\
\text { - Manage STRs as needed, } \\
\text { depending on patient's clinical } \\
\text { status. } \\
\text { - Document transfusion } \\
\text { conclusion (record "end } \\
\text { VSVs"). }\end{array}$ & $\begin{array}{l}\text { - Monitor and report } \\
\text { subacute adverse } \\
\text { sequelae ("lag } \\
\text { reactions"). } \\
\text { - Provide patient education } \\
\text { and posttransfusion } \\
\text { instructions. } \\
\text { - Plan discharge. } \\
\text { - Coordinate scheduling for } \\
\text { repeat hemotherapy as } \\
\text { needed. } \\
\text { - Follow up with select care } \\
\text { echelons for any STR } \\
\text { evaluation as needed. }\end{array}$ & $\begin{array}{l}\text { Biovigilance activities: } \\
\text { retrospective reviews; } \\
\text { tracer audits; periodic } \\
\text { automated EHR capture } \\
\text { and with review of all HT } \\
\text { events. Reporting to } \\
\text { national/state biovigilance } \\
\text { networks/programs. }\end{array}$ \\
\hline
\end{tabular}

Figure I Care map for uncomplicated hemotherapy (UHT), showing major diagnostic, therapeutic, and biovigilance activities and considerations associated with the various phases of a blood-transfusion event. See text for further details and information related to UHT care maps.

Note: Modified with permission from Andrzejewski C Jr, McGirr J. Nursing hemotherapy bedside biovigilance in the recognition and management of suspected transfusion reactions. In: Popovsky M, ed. Transfusion reactions, 4th edition, Bethesda, MD: AABB Press, 20I 2;55I-577.25

Abbreviation: HT, hemotherapy. 
Table 3 The twelve "rites" of hemotherapy
I. Right knowledge/reason
2. Right patient
3. Right testing
4. Right product
5. Right care locus
6. Right timing
7. Right volume
8. Right rate
9. Right monitoring, response, and follow-up
10. Right documentation
II. Right regulation
12. Right reimbursement

of suspected transfusion reactions (STRs), a variety of information can be obtained, potentially informing quality-improvement initiatives to decrease STR occurrence. Examining STRs from multiple perspectives potentially offers insights not only for individual patients' reactions but also into institutional system-quality/risk-management issues and increases our understanding of the basic biologic mechanisms involved in adverse HT reactions. Such approaches have been valuable in enhancing HT safety at our own institutions, and have resulted in a variety of system changes regarding HT monitoring and documentation. ${ }^{25}$ Decreases in febrile transfusion reaction rates after adoption of leukodepleted product inventories serves as another example using such analytic perspectives to enhance HT safety. ${ }^{30}$ Additional lessons learned from other STR case-generated quality initiatives will be included in the next few sections.

\section{Selected contemporary challenges in $\mathbf{H T}$}

As can be seen in Table 3, recurrent themes occur when one surveys the concerns and hazards of HT over time. Although new challenges may emerge at any time, the tenacity of many of the previously identified ones is a sobering consideration. Discussed in the following sections are some of the contemporary challenges confronting transfusion safety in the twenty-first century.

\section{Patient/specimen-identification issues}

In the earliest days of HT, the patient and donor were not only in physical proximity to one another, but were even physically attached when the direct-transfusion technique was used. Such clinical circumstances limited patient/specimen-identification problems provided that both donor and patient were accurately identified initially. With the introduction of citrated
Table 4 Potential classification basis of suspected transfusion reactions (STRs)

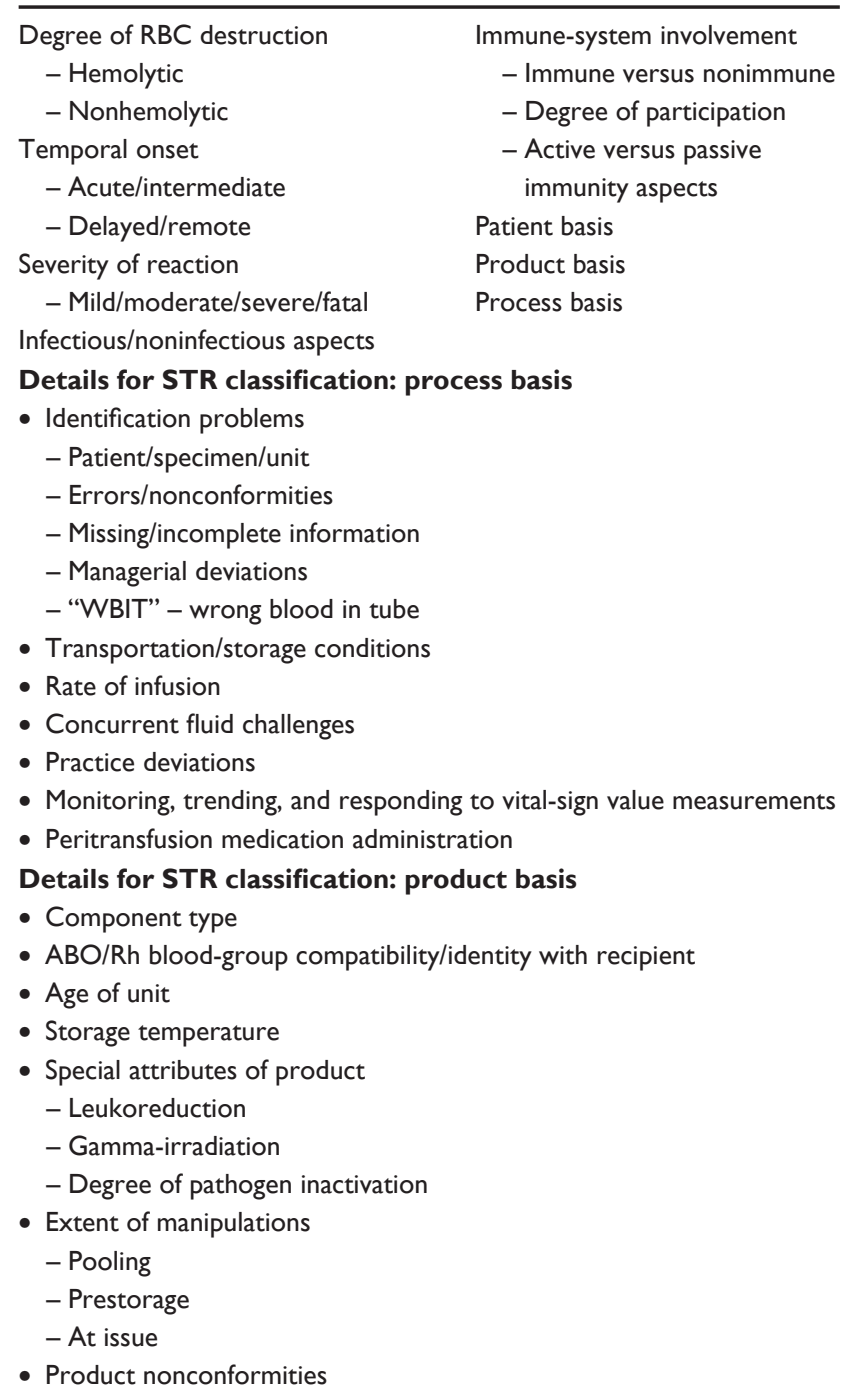

Abbreviation: RBC, red blood cell.

preservation solutions, indirect transfusion techniques, and enhanced refrigerated blood-storage processes that allowed blood to be collected and stored for longer time periods until needed along with the advent of cross-matching, the requirements for accurate specimen identification involving the patient and the donor problematically increased. Ever since then, BBs have struggled to ascertain that the specific unit of blood for transfusion and the specific intended recipient are clearly identified and appropriately matched.

ABO-incompatible transfusions have been reported to occur at a rate of one in $38,000 .{ }^{31}$ This equates to one $\mathrm{ABO}$ mismatch transfusion every 2-3 years at an average large hospital, indicating that $\mathrm{ABO}$-incompatible transfusions present a greater noninfectious risk than the most commonly feared infectious risks of hepatitis B, hepatitis C, and 
HIV/acquired immunodeficiency syndrome. ${ }^{31,32}$ To better understand this misidentification-associated risk and mitigate it, the process of patient and sample identification can be analytically separated into three sequential phases - initial specimen collection (preanalytic phase; area IA on HT care map), laboratory testing (analytic phase; area IA on the HT care map), and transfusion of product (postanalytic phase; area IB on the HT care map) - and subsequently examined for opportunities to prevent identification errors in each.

For example, upon specimen reception in the laboratory, the $\mathrm{BB} / \mathrm{TMS}$ is required to compare the $\mathrm{ABO}$ type of the current sample against its historical records. Most (60\%) require two separate ABO typings for patients without a historical type (many institutions requiring two different specimens) before issuing nonemergent non-group $\mathrm{O}$ red blood cells (RBCs). ${ }^{33}$ Furthermore, the process of cross-matching (either serological or electronic) itself is subject to rigorous quality control and regulatory/accreditation agency purview. The final phase of HT is also tightly controlled by rigorous policies and procedures. Two individuals must read and compare the information on the unit of blood with the patient's armband. Only then should the transfusion proceed.

We know that most identification errors resulting in mistransfusion occur outside the laboratory, with $20 \%$ of all mistransfusions ultimately being traced to patient misidentification or sample mislabeling. ${ }^{31}$ Therefore, labeling criteria have been standardized, and deviations in any aspect of the specimen labeling typically result in sample rejection and the need for redrawing of a new, properly identified specimen. $\mathrm{BBs}$ are justified in such strict rejection criteria, since samples that do not meet labeling criteria are 40 times more likely to have an $\mathrm{ABO}$-grouping discrepancy. ${ }^{34}$

Regardless of all these precautions, the blood inside the specimen tube may not match the specimen label. Studies have shown that the wrong blood in tube (WBIT) rate is appreciable and can vary among institutions, with results from one international study involving 62 hospitals in ten countries showing a median WBIT incidence of one in 1,986. ${ }^{35,36}$ As strategies to decrease WBIT occurrences, some institutions (like those of three of the authors) have implemented stringent polices regarding the need for doublewitness attestations for all BB specimens (area IA on the HT care map), similar to double-witness attestation protocols used in the transfusion of blood products (area IB on the HT care map), since the initial specimen-acquisition time can be one of the most vulnerable aspects of the HT process.

Despite the implementation of various intra- and extralaboratory safety measures, patient/specimen-misidentification problems most will likely remain a challenge to TM specialists well into the twenty-first century.

\section{Patient blood management}

Conservative blood utilization has been shown to be advantageous for certain patient populations, and at least not harmful in many cases. ${ }^{37-39}$ "Restrictive transfusion strategies" have been recommended by the AABB, formly known as the American Association of Blood Banks. ${ }^{40}$

Principles of patient blood management (PBM) include "managing anemia", "optimizing coagulation", "patientcentered decision making", and the use of "interdisciplinary blood conservation modalities", ${ }^{41,42}$ These and related principles have applicability across the different areas of the HT care map. ${ }^{41-47}$ Preoperative optimization of patients (areas IA and IB of the HT care map) includes evaluation/treatment for preoperative anemia and coagulopathies. Such preparations include detailed clinical evaluations of the patient's medical/ surgical histories (especially of any bleeding/coagulopathy problems) physical examination, medication reconciliation, especially noting the presence of drugs potentially impairing coagulation or erythropoiesis, and laboratory testing. ${ }^{42-47}$ If found, anemia may be treated pharmacologically with iron therapy, $\mathrm{B}_{12}$ /folate supplementation, and proerythropoietic agents, such as erythropoietin. ${ }^{46,47}$ Although the effectiveness of iron therapy or erythropoietin administration in improving patient outcomes and reducing blood transfusions has been questioned, data exist indicating that erythropoietin when used alone or in combination with intravenous iron may be beneficial in decreasing transfusion requirements in some patient populations. ${ }^{48,49}$

Conservative blood-transfusion strategies can also be extended to the intraoperative and postoperative settings (areas II and IIIA on the HT care map), and include optimizing surgical techniques to minimize blood loss, using normovolemic hemodilution strategies or red cell-salvage technologies (either intraoperatively or postoperatively), and applying topical absorbable hemostatic and sealant agents to the surgical field. ${ }^{43,45-47,50,51}$ Pharmacologic agents (eg, tranexamic acid, aminocaproic acid, and desmopressin) and factor concentrates represent additional resources in the control of bleeding. ${ }^{43,47,52}$ Thermoregulatory management of patients and the timely correction of acid-base disturbances are additional adjunctive considerations. ${ }^{47}$

Thromboelastography and rotational thromboelastometry may help surgeons make more timely intraoperative decisions regarding "data-informed" targeted HT, thus eliminating a "catch-all kitchen-sink" approach to 
blood-product administration. ${ }^{46,53}$ Returning a patient to the operating theater after surgery to address unexpected or prolonged bleeding may also be necessary for the surgical correction of problematic bleeding blood vessels.

Standardizing blood-transfusion practices within an institution are key elements in achieving effective PBM. Two tools useful in doing this are clinical checklists and HT-practice algorithms pertinent to select patient populations requiring transfusion support. Availability of practice guidelines increases physician awareness of institutional care standards. Making changes requires participation and "buy-in" from the clinical and laboratory staff, but ultimately shifts in "institutional culture" may be needed for ongoing success.

Further challenges in PBM requiring practitioner-mindset changes include encouragement of the use of single-unit $\mathrm{RBC}$ transfusions and the hemodynamic and clinical status assessment/monitoring of the patient for the continuing need of blood products between planned sequential nonurgent multiple-unit tandem transfusions. The recognition by both bedside practitioners and BB/TMS staff that blood derivatives like clotting factors, albumin and intravenous immunoglobulin require bedside monitoring of the patient similar to those approaches used with conventional blood-component transfusions, even if such products are not issued by the BB/TMS, is another challenge in the area of PBM. With regard to the latter in the interest of total blood safety it should also be noted that the occurrence of any adverse events associated with these products, even if they are issued from the pharmacy, should be reported to the BB/TMS as suspected transfusion reactions and evaluated accordingly.

\section{Unrecognized/unreported STRs and $\mathrm{HT}$ nonconformities}

Perhaps not appreciated by many non-BB/TMS personnel are the many issues and problems that may be encountered outside the $\mathrm{BB}$ perimeter once products are issued, an example being the nonrecognition/nonreporting of STRs to the BB/TMS. ${ }^{25,54-56}$ Sole reliance on reports of problems or STRs only communicated by colleagues at the bedside during the peritransfusion period, although essential, is only part of the surveillance needing to be performed by the BB/ TMS for high-quality patient safety. Various governmental regulatory, accreditation, and professional entities have noted the importance of adverse event/outcome monitoring, and have issued guidance and standards to BBs/TMSs addressing this. ${ }^{7,8}$ Targeted efforts to obtain such additional information on issued products or HT processes are critical in the effective design of both bedside- and laboratory-based biovigilance programs to enhance blood safety. Operationally, this can be achieved in a variety of ways, including review of hospital-wide adverse-event databases, performance of routine "tracer audits", and periodic monitoring of pertinent electronic resources like HT documentation in EHRs.

Lessons learned from such biosurveillance activities at one of our institutions (Baystate Health) have resulted in several changes in our HT monitoring/documentation and educational/training processes over the years. Inclusion of information regarding the various signs and symptoms of STRs in educational modules for nursing, ongoing discussions of selected reported STR case outcomes in various clinical care and quality-improvement committees, grand round presentations, and computer-assisted reporting of STRs via our HT EHR have all been used to increase awareness of the problem. Based on discussions with nursing staff, we have also modified the BB/TMS notification policy/process for STR reporting if the physician ordering the transfusion refuses to order an investigation such that nursing staff can now order an STR evaluation using the BB/TMS medical director as the ordering physician of record. Such an approach augments compliance with STR reporting, and can lessen unintentional practitioner stress that may result from professional disagreements at the bedside.

Many of the aforementioned issues occur in the immediate peritransfusion period (areas I and II on the HT care map). Nonrecognition/nonreporting of HT adverse sequelae can also occur more distally from the provocative transfusion event (area IIIB on the HT care map). Examples include RBC alloimmunization and notification of the BB/TMS of potential cases of posttransfusion hepatitis or other infectious agent disease transmission, transfusion-associated graft-versus-host disease, and transfusional iron overload. Regulatory agencies and accreditation organizations acknowledge the importance of such delayed adverse transfusion sequelae reporting, and include requirements for it in their institutional evaluations and certifications. For the most part, the BB/TMS has only limited and indirect control of this reporting activity, and must rely on astute clinicians to make the disease connection to the earlier HT.

We recently evaluated two cases of delayed adverse transfusion sequelae, one involving a potential hepatitis $\mathrm{C}$ transmission (not confirmed after appropriate follow-up investigations) and a transfusion-associated babesia transmission (confirmed after appropriate follow-up investigations). Notification to the BB/TMS in the latter situation was by 
an infectious disease specialist after the hospital laboratory noted an incidental finding by a staff pathologist in a flagged blood-smear review that showed RBCs with intracellular organisms suggestive of babesiosis. In the former case, notification was communicated by staff from the Commonwealth of Massachusetts Department of Public Health involved in a state surveillance program for this disease. State/province or national hemovigilance organizations conducting such biosurveillance programs and hospital laboratory-notification protocols offer opportunities in enhancing both transfusionrecipient and donor safety and should be encouraged.

Focusing on HT events and activities outside the BB/TMS also can lead to some unexpected opportunities to enhance practice and increase understanding of basic aspects of HT, as we will explore further in the next few sections.

\section{Transfusion-associated adverse pulmonary sequelae}

Transfusion-associated adverse pulmonary sequelae (TAAPS) represent a commonly encountered HT hazard secondary to a variety of causes. HT-related respiratory complications have been recognized since the transfusion's introduction into clinical practice, and may be a reflection of an increased sensitivity of the pulmonary circuit to physical/chemical stressors and immunologic processes. ${ }^{57-59}$ The differential diagnosis list for TAAPS includes 1) transfusion-associated circulatory overload (TACO), 2) transfusion-related acute lung injury (TRALI), 3) transfusion-associated dyspnea, 4) allergic/anaphylactic reactions, 5) transfusion-transmitted bacterial sepsis, 6) hemolytic reactions, and 7) intercurrent illness/underlying clinical condition(s). Although each of these conditions can increase morbidity or even be lifethreatening, the greatest concerns, due to their more frequent occurrences, relate to TRALI and TACO.

Depending on which data sources are examined, TRALI ranks somewhere in the top three of most common adverse HT events. ${ }^{16,23,60-62}$ Originally thought to be due solely to immune etiologies involving anti-human leukocyte antigen and/or antigranulocyte antibodies, other avenues for TRALI induction have been identified involving such biologic mediators as bioactive lipids. ${ }^{60-62}$ Great success has been achieved in decreasing the incidence of TRALI through various mitigation strategies, including diverting female plasma away from fresh-frozen plasma production or using plasma only from female donors periodically tested for the potential provocative antibodies. The application of similar mitigation strategies to the platelet inventory is currently being debated, and concerns about increased product shortages and blood product-acquisition costs have been raised. TRALI, however, can still occur even with tested plasma products and untested nonplasma products; it remains a concern and challenge needing further study in the TM community. ${ }^{60-62}$

Closely paralleling TRALI in its clinical presentation and potential severity is TACO, which we will now explore.

\section{TACO: an old nemesis}

Regardless of how it was referred to (eg, acute heart dilation, circulatory overload/overloading/hypervolemia, etc, see Table 2), TACO has been recognized as an adverse HT-recipient event since transfusion's earliest days. ${ }^{1,4,19}$ During that time, surgeons, prized for their technical skills in establishing direct arterial-venous anastomoses in the direct transfusion techniques used to exchange whole blood between donors and patients, realized that both the volume and rate of blood transfer could easily overwhelm a recipient's circulatory system capacity if the "fluid challenge" was not carefully monitored and adjusted to prevent such volume overloading. ${ }^{4}$ With the advent of indirect transfusion techniques, the decreased use of whole blood and the introduction of targeted-component therapy, concerns regarding TACO were diminished. Although its potential occurrence continued to be duly noted, its importance as an adverse HT consequence waned, with some practitioners becoming nonchalant and dismissive of it. Only in the past two decades has renewed interest in it occurred, with routine tracking of it in most national hemovigilance networks, as well as by hospitals and local state/province regulatory bodies. ${ }^{16,27,36,63-68}$ Unfortunately, the increased recognition of TACO as a major adverse HT event by the TM community has not necessarily occurred in non-TM specialties. It is perhaps this latter aspect that presents one of the greatest challenges to the TM community today.

In the hospital system of three of the authors, we have been interested in TACO diagnosis and mitigation/prevention since the mid-1990s, and have evolved several aspects of our blood ordering, transfusion documentation, and provider education since that time..$^{25,66,69-71}$ A major aspect of our quality-improvement activities in this regard has focused on the bedside monitoring of the patient, especially the recording and documentation of the patient's vital-sign values (VSVs). ${ }^{69-71}$ The routine monitoring (ie, "bedside biovigilance") of a patient's VSVs and the patient's clinical status during HT have been well recognized in nursing for generations, but variability in practice exists regarding how often VSVs should be recorded and clinical assessments of the patient be performed. ${ }^{25}$ In our hospital system, nurses 
routinely involved in HT have been particularly strong allies and advocates in helping us to design and implement some of the strategies involved in this bedside biovigilance, and their participation in enhancing transfusion safety, especially as it relates to issues regarding infusion rates, multi-blood product-order requests, and the recognition of potential STRs, is crucial in any meaningful bedside biovigilance initiative. Additional strategies that we endorse and some that have been implemented by others involve the construction of patient risk-profiling tools or computerized alerting systems that can identify clinically vulnerable patients, potentially mitigating TACO's occurrence and severity. ${ }^{72-75}$

\section{Electronic health records and "big data"}

As in other medical fields, the increasing use of computerized record keeping in TM brings new opportunities and new challenges to the discipline. ${ }^{14,15,17}$ Although computerization in laboratories and BBs has existed for decades (eg, records of serologic testing, cross-matching results, history of units issued, etc), few data elements are typically shared across computer interfaces with the patient's EHR (eg, ABO type, antibodies identified, direct antiglobulin test results, etc). ${ }^{15}$ With governmental mandates in some countries and with just increasing electronic integration interests in others, the need for the BB/TMS to "meaningfully interact" within the patient's electronic record has become of paramount importance. Several barriers, however, thwart individuals in trying to accomplish such electronic connections, including issues with software/middleware/hardware compatibilities, interface connections, institutional firewall and security concerns, and lack of qualified staff to develop and maintain such systems. Nevertheless, commitment to such initiatives is being moved forward by TM professionals, and tangible benefits have been realized. ${ }^{76}$ The areas of computerized physician/provider order entry and clinical decision support systems are two electronic functionalities embraced by the TM community contributing to enhanced blood management and HT safety. ${ }^{77,78}$ Although the generation of provider alerts by such "electronic colleagues" may help in decreasing HT usage, they may not be sufficient in and of themselves to substantially modify practitioner behavior in all HT settings. ${ }^{79}$ The voluminous amount of potential HT data and the associated problems transforming it into actionable HT information has also been identified as a challenge facing the discipline today. ${ }^{17}$ As we shall discuss in the next section, informatics in the $\mathrm{BB} / \mathrm{TMS}$ has ramifications regarding staffing concerns as well.

\section{Skilled staff shortages and the maintenance of competency}

Regardless of institutional size, multiple issues currently face any BB/TMS in maintaining adequately trained and competent personnel to conduct its daily operations. These issues are of international relevance as well.

The size and complexity of any particular BB/TMS dictates its staffing requirements. In smaller institutions, this can mean BB/TMS staffing with generalist laboratory staff. Larger institutions, including regional centralized BB/TMS entities, may have variously educated staff at multiple talent levels (medical laboratory scientists, medical laboratory technologists/technicians, laboratory assistants, transfusion safety officers, etc). Some BBs/TMSs may also offer blooddonor collection programs, requiring additionally trained phlebotomists with knowledge of donor qualifications/deferral requirements and the technical aspects pertinent to the collection/processing of components. Even more complex are $\mathrm{BBs} / \mathrm{TMSs}$ that support apheresis-medicine services whose clinical staff and nurses are directly involved in bedside care of patients.

All of these service models require an organizational structure defining leadership and responsibility. A welldefined organizational structure helps ensure effective and compliant organizations. Standards from such accrediting organizations as the AABB and the College of American Pathologists indicate that each service be led by a licensed physician qualified by training or experience to serve as the medical director with responsibility and authority for all medical and technical policies and procedures. ${ }^{7,80}$ Some organizations may also employ quality officers and transfusion-safety officers as well; regardless of whether positions are titled as such, the duties they perform are required by regulatory guidance. . $^{76,81}$

Addressing the contemporary challenges of adequate and qualified staffing levels involves not only finding and hiring the right individuals to suit institutional needs but also their training, competence assessment/maintenance, and long-term retention of these candidates in a competitive and ever-changing health care environment. The US Bureau of Labor Statistics projects a need of at least 14,000 new laboratory professionals annually, despite current limited numbers of educational programs producing only 5,000 potentially qualified individuals per annum. ${ }^{82}$ Similar needs and asset restrictions undoubtedly apply outside the US as well. Given such projections, laboratory medicine and TM champions in particular are required to help promote their respective specialty areas, providing opportunities for continuing 
professional education and growth within them to make the disciplines more attractive to potential candidates.

Several tactics can be used to address hiring and retention challenges. Communication with key institutional executive leadership about the complexities of the services performed by the BB/TMS staff is vital. Implementation of automation in serologic testing and adoption of electronic cross-matching strategies may increase efficiency and help decrease manual labor of the staff. Offering flexible work-shift schedules along with salary-enhancement packages and the creation of "career ladder" opportunities for technical staff can also help to attract qualified candidates. These individuals can become more clinically involved in a variety of activities ranging from specialized projects in the laboratory to biovigilance-supporting activities, such as database development/maintenance and involvement with multidisciplinary care teams outside the BB/TMS. This latter aspect can enhance professional development, leading to increased job satisfaction and more engaged staff, with more hopeful prospects for long-term staff retention. Such engagement also fosters an environment encouraging creative and innovative thought and solutions, leading to enhanced HT safety.

Despite these efforts, integration in a modern health care environment requires additional skills, including the ability to master multiple and specialized computer systems. Staff may be called upon to help develop and maintain various computer systems, laboratory and clinical interfaces, and informatics networks, regardless of having traditional educational backgrounds typically lacking such digital asset exposure. In the age of computerized physician/provider order entry, with the ability to incorporate mechanisms to promote enhanced patient and HT safety, staff in the BB/TMS are expected to perform in a high-functioning and collaborative manner with respect to the sometimes multiple layers of informatics systems used in the daily performance of their routine work. Staff may need to access multiple computer systems, thus requiring abilities to learn, comprehend, and retain unique knowledge pertinent to each electronic system. "Digital troubleshooting" becomes a major challenge when these systems are interfaced or integrated, because this will typically involve information technology staff to help unravel the problem and correct the situation. This can put a major strain on BB/TMS staffing, particularly during non-core-hour shifts, when there are fewer staff members present or in emergent/ urgent situations, where the lengths of test/result-turnaround times or product-preparation times are critical. We anticipate that assigning select individuals solely dedicated to electronic support functions in the BB/TMS most likely will become the norm rather than the exception.

\section{The most compelling challenge}

Space limitations preclude us from a detailed discussion of all the concerns and issues identified in Table 2. No doubt other issues could be added to the list from other colleagues' perspectives, and depending on one's viewpoint, any one of these issues could legitimately be advocated as the most pressing and worrisome. There is one challenge for which the TM community must always be vigilant. That challenge is clinical complacency, the acceptance of the status quo. There will always be a need for improving the things we do for the patients and donors whose care is entrusted to us, regardless of the financial considerations and logistical constraints. Failure to heed and meet this challenge not only compromises the clinical care we provide but also the scientific discovery processes necessary to continue to advance our basic science knowledge of HT and enhance its safety.

\section{Summary}

In this review, we have explored some of the contemporary challenges confronting HT in the context of the history of blood transfusion, the HT care map, and the various HT "rites" associated with the delivery of safe and efficacious patient care. When viewed through the lens of history, recurrent themes regarding HT safety concerns and challenges emerge. Although great strides have occurred in increasing HT safety over the years, opportunities remain to further enhance transfusion safety from both laboratory and bedside focused biovigilance perspectives. Cooperative initiatives between accreditation and regulatory entities, blood collectors and suppliers, and hospital transfusion services and health care providers involved in the bedside care of the patient offer the best approaches in further mitigating adverse HT sequelae and nonconformities that may arise in the daily operations of a contemporary BB/TMS.

\section{Disclosure}

The authors report no conflicts of interest in this work.

\section{References}

1. Maluf NS. History of blood transfusion. J Hist Med Allied Sci. 1954;9(1):59-107.

2. Haeger K. Medicine becomes a science. In: Haeger K, editor. The Illustrated History of Surgery. New York: Bell; 1988:117-141.

3. Greenwalt TJ. A short history of transfusion medicine. Transfusion. 1997;37(5):550-563.

4. Bernheim BM. Blood Transfusion Hemorrhage and the Anemias. Philadelphia: Lippincott; 1917. 
5. Tucker H. Blood Work: A Tale of Medicine and Murder in the Scientific Revolution. New York: WW Norton; 2011.

6. Schmidt PJ. The plasma wars: a history. Transfusion. 2012; 52 Suppl 1:2S-4S.

7. Mintz PD. Quality assessment and improvement of blood transfusion practices. In: Mintz PD, editor. Transfusion Therapy: Clinical Principles and Practices. 3rd ed. Bethesda (MD): AABB; 2011:813-836.

8. Hess JR, Smit Sibinga CT, Mintz PD. History of quality management in transfusion medicine. In: Smit Sibinga CT, editor. Quality Management in Transfusion Medicine. New York: Nova Biomedical; 2013:1-34.

9. Whitby L. Transfusion in war and peace. Lancet. 1945;245(6332): $1-4$.

10. Hedley-Whyte J, Milamed DR. Blood and war. Ulster Med J. 2010;79(3):125-134.

11. Epstein J, Jaffe HW, Alter HJ, Klein HG. Blood system changes since recognition of transfusion-associated AIDS. Transfusion. 2013; 53(10 Pt 2):2365-2374.

12. Stramer SL, Hollinger FB, Katz LM, et al. Emerging infectious disease agents and their potential threat to transfusion safety. Transfusion. 2009;49 Suppl 2:1S-29S.

13. Galel SA. Infectious disease screening. In: Roback JD, Grossman BJ, Harris T, Hillyer CD, editorss. Technical Manual. 17th ed. Bethesda: AABB; 2011:239-270.

14. Rothman B, Leonard JC, Vigoda MM. Future of electronic health records: implications for decision support. Mt Sinai J Med. 2012;79(6): 757-768.

15. Sharma G, Parwani AV, Raval JS, Triulzi DJ, Benjamin RJ, Pantanowitz L. Contemporary issues in transfusion medicine informatics. J Pathol Inform. 2011;2:3.

16. Bolton-Maggs PHB, Cohen H. Serious hazards of transfusion (SHOT) haemovigilance and progress is improving transfusion safety. $\mathrm{Br} J$ Haematol. 2013;163(3):303-314.

17. Skeate RC. Transfusion medicine data as product. Transfusion. 2013;53(6):1153-1156.

18. Whitby LE. The hazards of transfusion. The Lancet. 1942;239(6194): 581-585.

19. Scott RB. Complications of blood transfusion (section III). In: Keyes G, Brewer HF, editors. Blood Transfusion. Baltimore: Williams and Wilkins; 1949:133-210.

20. Anstall HB, Blaylock RC, Craven CM. Managing Hazards in the Transfusion Service. Chicago: ASCP; 1993.

21. Pandey S, Vyas GN. Adverse effects of plasma transfusion. Transfusion. 2012;52 Suppl 1:65S-79S.

22. Nance ST, editor. Blood Supply: Risks, Perceptions and Prospects for the Future. Bethesda (MD): American Association of Blood Banks; 1994.

23. Mazzei CA, Popovsky MA, Kopko PM. Noninfectious complications of blood transfusions. In: Roback JD, Grossman BJ, Harris T, Hillyer CD, editors. Technical Manual. 17th ed. Bethesda (MD): AABB; 2011:727-762.

24. Petrides M, AuBuchon JP. To transfuse or not to transfuse: an assessment of risks and benefits. In: Mintz PD, editor. Transfusion Therapy: Clinical Principles and Practice. 3rd ed. Bethesda (MD): AABB; 2011:855-899.

25. Andrzejewski C Jr, McGirr J. Nursing hemotherapy bedside biovigilance in the recognition and management of suspected transfusion reactions. In: Popovsky MA, editor. Transfusion Reactions. 4th ed. Bethesda (MD): AABB; 2012:551-577.

26. Murphy MF, Saxena S, Smit Sibinga CT. Patient safety and quality management at the clinical interface. In: Smit Sibinga CT, editor. Quality Management in Transfusion Medicine. New York: Nova Biomedical; 2013:283-314.

27. Taylor C. Clinical activities: medical decision-making, sampling, ordering components, administration, and patient monitoring. In: De Vries RR, Faber JC, editors. Hemovigilance: An Effective Tool for Improving Transfusion Safety. Chichester, UK: Wiley-Blackwell; 2012:126-143.
28. Oldham J, Sinclair L, Hendry C. Right patient, right blood, right care: safe transfusion practice. Br J Nurs. 2009;18(5):312, 314, 316-320.

29. Burns C. The 8 rights of transfusion administration. 2012. Available from: http://thebloodytruth.com/the-8-rights-of-transfusionadministration. Accessed December 31, 2013.

30. Heddle NM, Webert KE. Febrile nonhemolytic transfusion reactions. In: Popovsky MA, editor. Transfusion Reactions. 4th ed. Bethesda (MD): AABB; 2012:53-97.

31. Linden JV, Wagner K, Voytovich AE, Sheehan J. Transfusion errors in New York State: an analysis of 10 years' experience. Transfusion. 2000;40(10):1207-1213.

32. Luban NL. Transfusion safety: where are we today? Ann NY Acad Sci. 2005;1054:325-341.

33. Grimm E, Friedberg RC, Wilkinson DS, AuBuchon JP, Souers RJ, Lehman CM. Blood bank safety practices - a Q-Probes analysis of 122 clinical laboratories. Arch Pathol Lab Med. 2010;134(8): 1108-1115.

34. Lumadue JA, Boyd JS, Ness PM. Adherence to a strict specimenlabeling policy decreases the incidence of erroneous blood grouping of blood bank specimens. Transfusion. 1997;37(11-12): 1169-1172.

35. Dzik WH, Murphy MF, Andreu G, et al. An international study of the performance of sample collection from patients. Vox Sang. 2003;85(1):40-47.

36. Stubbs JR, Bundy KL, van Buskirk CN. Preventing transfusion reactions. In: Popovsky MA, editor. Transfusion Reactions. 4th ed. Bethesda (MD): AABB; 2012:597-647.

37. Hébert PC, Wells G, Blajchman MA, et al. A multicenter, randomized, controlled clinical trial of transfusion requirements in critical care. Transfusion Requirements in Critical Care Investigators, Canadian Critical Care Trials Group. N Engl J Med. 1999;340(6):409-417.

38. Yaffee DW, Smith DE 3rd, Ursomanno PA, et al. Management of blood transfusion in aortic valve surgery: impact of a blood conservation strategy. Ann Thorac Surg. 2014;97(1):95-101.

39. Carson JL, Charles PA, Herbert PC. Transfusion thresholds and other strategies for guiding allogeneic red blood cell transfusion. Cochrane Database Syst Rev. 2012;4:CD002042.

40. Carson JL, Grossman BJ, Kleinman S, et al. Red blood cell transfusion: a clinical practice guideline from the AABB. Ann Intern Med. 2012;157(1):49-58.

41. Society for the Advancement of Blood Management 2013. Available from: http://www.sabm.org/sites/www.sabm.org/files/SABM-Matrix. pdf. Accessed December 22, 2013.

42. Hohmuth B, Ozawa S, Ashton M, Melseth RL. Patient-centered blood management. J Hosp Med. 2014;9(1):60-65.

43. Seeber P, Shander A. Basics of Blood Management. 2nd ed. Chichester: Wiley-Blackwell; 2013.

44. Kumar A, Figueroa PI, Gowans KL, et al. An evolution in blood management: past, present, and future. Qual Manag Health Care. 2011;20(4):311-321.

45. Ozawa S. Patient blood management: use of topical hemostatic and sealant agents. AORN J. 2013;98(5):461-478.

46. Kumar A, Auron M, Ereth M. Blood management. Anesthesiol Clin. 2013;31(2):433-450.

47. Waters JH. Patient blood management. In: Roback JD, Grossman BJ, Harris T, Hillyer CD, editors. Technical Manual. 17th ed. Bethesda (MD): AABB; 2011:671-685.

48. Kapadia BH, Banerjee S, Issa K, McElroy MJ, Harwin SF, Mont MA. Preoperative blood management strategies for total knee arthroplasty. J Knee Surg. 2013;26(6):373-378.

49. Lin DM, Lin ES, Tran M. Efficacy and safety of erythropoietin and intravenous iron in perioperative blood management: a systematic review. Transfus Med Rev. 2013;27(4):221-234.

50. Banerjee S, Kapadia BH, Issa K, et al. Postoperative blood loss prevention in total knee arthroplasty. J Knee Surg. 2013;26(6): 395-400.

51. Waters JH. Intraoperative blood recovery. ASAIO J. 2013;59(1):11-17. 
52. CRASH-2 trial collaborators, Shakur H, Roberts I, et al. Effects of tranexamic acid on death, vascular occlusive events, and blood transfusion in trauma patients with significant haemorrhage (CRASH-2): a randomized, placebo-controlled trial. Lancet. 2010;376(9734):23-32.

53. Bolliger D, Tanaka KA. Roles of thromboelastography and thromboelastometry for patient blood management in cardiac surgery. Transfus Med Rev. 2013;27(4):213-220.

54. Yeh SP, Chang CW, Chen JC, et al. A well-designed online transfusion reaction reporting system improves the estimation of transfusion reaction incidence and quality of care in transfusion practice. Am J Clin Pathol. 2011;136(6):842-847.

55. Siegenthaler MA, Schneider P, Vu DH, Tissot JD. Haemovigilance in a general university hospital: need for a more comprehensive classification and codification of transfusion-related events. Vox Sang. 2005;88(1):22-30.

56. Thomas J, Baffa A, Nienhaus, Hannon T. Underrecognition and underreporting of the pulmonary complications to transfusion. Transfusion. 2012;52 Suppl:8A.

57. Mollison PL, Engelfriet CP, Contreras M, editors. Blood Transfusion in Clinical Medicine. 8th ed. Oxford: Blackwell Scientific; 1987;116.

58. Bux J, Sachs UJH. Pulmonary transfusion reactions. Transfus Med Hemother. 2008;35(15):337-345.

59. Andrzejewski C Jr, Popovsky MA. Transfusion-associated adverse pulmonary sequelae: widening our perspective. Transfusion. 2005;45(7): 1048-1050.

60. Kleinman S, Caulfield T, Chan P, et al. Toward an understanding of transfusion-related acute lung injury: statement of a consensus panel. Transfusion. 2004;44(12):1774-1789.

61. Shaz BH, Stowell SR, Hillyer CD. Transfusion-related acute lung injury: from bedside to bench and back. Blood. 2011;117(5):1463-1471.

62. Makar RS, Powers A, Stowell CP. Reducing transfusion-related acute lung injury risk: evidence for and approaches to transfusion - related acute lung injury mitigation. Transfus Med Rev. 2012;26(4):305-320.

63. Popovsky MA, Taswell HF. Circulatory overload: an underdiagnosed consequence of transfusion. Transfusion. 1985;25:469.

64. Food and Drug Administration. Fatalities Reported to FDA Following Blood Collection and Transfusion: Annual Summary for Fiscal Year 2010. Rockville (MD): CBER Office of Communication, Outreach, and Development; 2011. Available from: http://www fda.gov/downloads/BiologicsBloodVaccines/SafetyAvailability/ ReportaProblem/TransfusionDonationFatalities/UCM254860.pdf. Accessed February 28, 2012.

65. Magee G, Zbrozek A. Fluid overload is associated with increases in length of stay and hospital costs: pooled analysis of data from more than 600 US hospitals. Clinicoecon Outcomes Res. 2013;5:289-296.

66. Popovsky MA, Audet AM, Andrzejewski C Jr. Transfusion-associated circulatory overload in orthopedic surgery patients: a multi-institutional study. Immunohematology. 1996;12(2):87-89.

67. Robillard P, Nawej K, Chapdelaine A. Transfusion-associated circulatory overload (TACO): current leading cause of transfusion associated fatalities reported to the Quebec Hemovigilance System. Transfus Med. 2009;19:280-281.
68. Narick C, Triulzi DJ, Yazer MH. Transfusion-associated circulatory overload after plasma transfusion. Transfusion. 2012;52(1):160-165.

69. Levy R, Pantanowitz L, Cloutier D, et al. Development of electronic record charting for hospital based transfusion and apheresis medicine services: early adoption perspectives. J Pathol Inform. 2010;1:8.

70. Andrzejewski C Jr, Popovsky MA, Stec TC, et al. Hemotherapy bedside biovigilance involving vital sign values and characteristics of patients with suspected transfusion reactions associated with fluid challenges: can some cases of transfusion associated circulatory overload have proinflammatory aspects? Transfusion. 2012;52(11):2310-2320.

71. Andrzejewski C Jr, Casey MA, Popovsky MA. How we view and approach transfusion-associated circulatory overload: pathogenesis, diagnosis, management, mitigation and prevention. Transfusion. 2013;53(12):3037-3047.

72. Finlay HE, Cassorla L, Feiner J, Toy P. Designing and testing a computer-based screening system for transfusion-related acute lung injury. Am J Clin Pathol. 2005;124(4):601-609.

73. Clifford L, Singh A, Wilson GA, et al. Electronic health record surveillance algorithms facilitate the detection of transfusion-related pulmonary complications. Transfusion. 2013;53(6):1205-1216.

74. Murphy EL, Kwaan N, Looney MR, et al. Risk factors and outcomes in transfusion-associated circulatory overload. Am J Med. 2013;126(4):357. e29-e38.

75. Lieberman L, Maskens C, Cserti-Gazdewich C, et al. A retrospective review of patient factors, transfusion practices, and outcomes in patients with transfusion-associated circulatory overload. Transfus Med Rev. 2013;27(4):206-212.

76. Donald T. EMR adoption brings benefits to transfusion medicine. $A A B B$ News. 2013;(10):12-17.

77. Murphy MF, Fraser E, Miles D, et al. How do we monitor hospital transfusion practice using an end-to-end electronic transfusion management system? Transfusion. 2012;52(12):2502-2512.

78. Yazer MH, Walters JH. How do I implement a hospital-based blood management program? Transfusion. 2012;52(8):1640-1645.

79. Collins RA, Triulzi D, Waters JH, Reddy V, Yazer MH. Evaluation of real-time clinical decision support systems for platelet and cryoprecipitate orders. Am J Clin Path. 2014;141(1):78-84.

80. Carson TH. Organization. In: American Association of Blood Banks, editor. Standards for Blood Banks and Transfusion Services. 28th ed. Bethesda (MD): AABB; 2012:1-2.

81. Carson TH. Deviations, nonconformances, and adverse events. In: American Association of Blood Banks, editor. Standards for Blood Banks and Transfusion Services. 28th ed. Bethesda (MD): AABB; 2012:79-83.

82. Beigel D. The healthcare system's perfect storm: the clinical laboratory community faces changes and strategic challenges. Available from: http://laboratory-manager.advanceweb.com/Web-Extras/Online-Extras/ The-Healthcare-Systems-Perfect-Storm.aspx. Accessed December 26, 2013.
International Journal of Clinical Transfusion Medicine

\section{Publish your work in this journal}

International Journal of Clinical Transfusion Medicine is an international, peer-reviewed, open access, online journal publishing clinicalexperimental, policy-making and evidence-based practices of all topics pertaining to clinical transfusion medicine. Original research, short reports, reviews, case reports and commentaries are invited.

\section{Dovepress}

The manuscript management system is completely online and includes a very quick and fair peer-review system, which is all easy to use. Visit http://www.dovepress.com/testimonials.php to read real quotes from published authors. 